\title{
Escala de avaliação de incapacidade na demência - versão longa (DADL-BR)
}

\author{
Mariana Boaro Fernandez Canon ${ }^{\mathrm{a}}$, Maria Helena Morgani de Almeida ${ }^{\mathrm{b}}$, \\ Marcia Maria Pires Camargo Novellic
}

\author{
${ }^{a}$ Universidade Federal de São Paulo - UNIFESP, Santos, SP, Brasil. \\ ${ }^{\text {b}}$ Departamento de Fisioterapia Fonoaudiologia e Terapia Ocupacional, Universidade de São Paulo - USP, \\ São Paulo, SP, Brasil. \\ 'Departamento de Gestão e Cuidado em Saúde, Instituto de Saúde e Sociedade - ISS, \\ Universidade Federal de São Paulo - UNIFESP, Santos, SP, Brasil.
}

\begin{abstract}
Resumo: Introdução: Não há disponível na literatura instrumentos de avaliação funcional para idosos com demência que avaliem todas as ocupações. Objetivo: Elaborar a Versão Longa da Escala de Avaliação de Incapacidade na Demência (DADL-Br), que avalie todas as Ocupações previstas pela Associação Americana de Terapia Ocupacional (AOTA), bem como atividades que as compõem, e verificar sua validade de conteúdo. Método: Com a autorização da autora principal da versão original (DAD), Profa. Dra. Isabelle Gélinas, os novos itens da Versão Longa (DADL-Br) foram elaborados a partir da classificação da AOTA para as Ocupações, considerando as lacunas existentes no instrumento original. Foram realizadas avaliações de Equivalências Cultural e Conceitual por um Comitê de Especialistas e um Comitê Multiprofissional. As sugestões dos Comitês foram aceitas e o processo seguiu para os pré-testes e análise da da autora. Resultados: Na primeira versão do instrumento foram acrescentados 10 novos domínios e 64 novos itens, que após sete avaliações da Equivalência Cultural (média da concordância 89,2\%), seis avaliações da Equivalência Conceitual (média da concordância $81,2 \%$ ), três pré-testes e análise da autora principal da versão original, resultaram na elaboração de cinco versões, acréscimo de doze itens e exclusão de sete, sendo a versão final composta por 20 domínios e 109 itens, destes 10 novos domínios e 69 novos itens. Conclusão: Esse processo conferiu validade de conteúdo ao DADL-Br, que contempla todas as Ocupações propostas pela AOTA, podendo ser uma ferramenta útil para avaliar o perfil de desempenho ocupacional de idosos com demência.
\end{abstract}

Palavras-chave: Avaliação, Atividades Cotidianas, Idoso, Demência, Reprodutibilidades dos Testes, Validade dos Testes.

\section{Disability assessment scale for dementia - long version (DADL-BR)}

\begin{abstract}
Introduction: There are no functional assessment tools for elderly with dementia available in the literature that will assess all occupations. Objective: To develop a Long Version of Disability Assessment for Dementia Scale (DADL-Br), covering all occupations provided by the American Association of Occupational Therapy (AOTA) and the activities that compose them and evaluate its content validity. Method: With the permission of the original version main author (DAD), Isabelle Gélinas $\mathrm{PhD}$, the new items of the Long Version (DADL-Br) were developed based on the classification proposed by AOTA for occupations, considering the gaps in the original instrument. We reviewed the Cultural and Conceptual Equivalence by the Expert Committee and Multidisciplinary Committee. The suggestions of the Committees were accepted and the process followed for the pre-test and author analysis. Results: The first version of the instrument received 10 new fields and 64 new items, which after seven reviews of
\end{abstract}

Autor para correspondência: Marcia Maria Pires Camargo Novelli, Departamento de Gestão e Cuidados em Saúde, Instituto de Saúde e Sociedade, Universidade Federal de São Paulo, Campus Baixada Santista, Rua Silva Jardim, 136, Vila Mathias, CEP 11015-020, Santos, SP, Brasil, e-mail: mnovelli@uol.com.br

Recebido em Jan. 13, 2015; 1ª Revisão em Fev. 6, 2015; 2ª Revisão em Ago. 28, 2015; Aceito em Dez. 9, 2015. 
Cultural Equivalence (average concordance 89.2\%), six reviews of Conceptual Equivalence (average concordance $81.2 \%$ ), tree pre-tests and analysis of the original version main author, has resulted in the development of five versions, addition of twelve items and exclusion of seven items, and the final version consists of 20 fields and 109 items, being 10 new fields and 69 new items. Conclusion: This process conferred the content validity of DADL-Br, which includes all occupations proposed by AOTA and can be a useful tool to evaluate the profile of occupational performance of elderly with dementia.

Keywords: Evaluation, Activities of Daily Living, Aged, Dementia, Reproducibility of Results, Validity of Tests.

\section{Introdução}

O envelhecimento populacional é considerado um fenômeno mundial e ocorre em ritmos diferentes nos diversos países, porém, em quase todo o mundo, a população idosa, referindo-se a pessoas acima de 60 anos em países desenvolvidos e acima de 65 anos em países em desenvolvimento, é a que apresenta o maior crescimento (ORGANIZAÇÃO..., 2012).

Segundo a Organização das Nações Unidas ONU (ORGANIZAÇÃO..., 2013), em 2013 havia 841 milhôes de idosos no mundo. Em poucos anos, essa população ultrapassará o total de crianças menores de cinco anos e isso acontecerá não apenas em países desenvolvidos. Em, aproximadamente, quatro décadas, $80 \%$ dos idosos viverão em países em desenvolvimento e emergentes (ORGANIZAÇÃO..., 2012).

O envelhecimento cursa com aumento da incidência de doenças crônicas, como o câncer, demências e doenças cardiovasculares, consideradas graves problemas de saúde pública (ORGANIZAÇĀO..., 2012), por ameaçarem a qualidade de vida da população que envelhece.

O DSM-V propôs, recentemente, a modificação da terminologia Demência para Transtornos Neurocognitivos, e os critérios diagnósticos destes são baseados na evidência do declínio de uma ou mais áreas do domínio cognitivo, documentado através de testes padronizados e que acarretem prejuízo na independência do indivíduo com relação às Atividades da Vida Diária (AVD). O mesmo documento apresenta os critérios para a divisão dos quadros em: Demência Vascular (DV), Doença de Alzheimer (DA), Frontotemporal, Corpos de Lewy, Lesão Cerebral Traumática, Doença de Parkinson, entre outras (ARAÚJO; LOTUFO NETO, 2014).

Burlá et al. (2013) realizaram uma revisão sistemática da literatura com o objetivo de projetar o número de idosos com demência no Brasil, em um futuro próximo. A taxa bruta de prevalência variou de $2,03 \%$ a $12,10 \%$, valor acima da taxa média para os países da América Latina (7,13\%). O estudo concluiu que haverá um pequeno crescimento na taxa de prevalência de demência na população com 65 anos ou mais, de 7,6\% para 7,9\% entre 2010 e 2020 , sendo 55 mil novos casos por ano.

As demências, em sua maioria, resultam de doenças neurodegenerativas crônicas e progressivas e estáo associadas a comprometimentos físicos e cognitivos que interferem profundamente na vida dos sujeitos, assim como de seus familiares/cuidadores. São doenças altamente incapacitantes, que comprometem de forma significativa o desempenho ocupacional, fazendo com que o indivíduo necessite de cuidados intensos e contínuos que podem causar ansiedade, depressão e sobrecarga aos familiares/cuidadores (CIETO et al., 2014).

O desempenho ocupacional é caracterizado pela interação complexa e dinâmica dos fatores do cliente (valores, crenças e espiritualidade, funçôes e estruturas do corpo); das habilidades de desempenho (motoras, sensoriais, cognitivas, emocionais e comunicativas); dos padróes de desempenho (hábitos, rotinas, rituais e papéis ocupacionais) e também do contexto do desempenho (cultural, pessoal, físico, social, temporal e virtual) (AMERICAN..., 2014).

Uma das formas de avaliar o desempenho ocupacional é através das Ocupações. Essas se organizam em atividades diárias com propósito, significado e senso de utilidade para aqueles que nelas se engajam (AMERICAN..., 2014).

Com o objetivo de abranger a totalidade das ocupaçôes, a American Occupational Therapy Association (AOTA) propóe os seguintes domínios de atividades: Atividades Básicas da Vida Diária (ABVD), Atividades Instrumentais da Vida Diária (AIVD), Descanso e Sono, Educação, Trabalho, Lazer, Brincar e Participação Social (AMERICAN..., 2014).

As ABVD podem ser descritas como as atividades voltadas para o cuidado do indivíduo com o próprio corpo e incluem: banho, controle de esfíncteres, vestuário, alimentação, comer, mobilidade funcional, cuidado com equipamentos pessoais, higiene pessoal e autocuidado, atividade sexual e uso do vaso sanitário (AMERICAN..., 2014). 
As AIVD são as atividades que necessitam da interação com o ambiente (casa e comunidade), são mais complexas e podem ser opcionais, incluem: cuidar de outras pessoas, cuidar de animais, educar crianças, uso de equipamentos para comunicação, mobilidade na comunidade, gerenciamento financeiro, manutenção e gerenciamento da saúde, gerenciamento do lar, preparação de refeição e posterior limpeza, práticas religiosas, procedimentos de segurança e reaçóes emergenciais e fazer compras (AMERICAN..., 2014).

O descanso é compreendido como repouso ou açóes sem esforços, promovendo um relaxamento, enquanto o sono é caracterizado pelo ato de dormir e permanecer adormecido. A educação inclui atividades relacionadas com a formação educacional e todo o seu contexto (aulas, intervalos, atividades extracurriculares, etc...), além da busca do indivíduo por novas informaçôes e conhecimentos em áreas de seu interesse, através de cursos, atividades e treinamento (AMERICAN..., 2014).

O trabalho é caracterizado como as atividades que provêm uma remuneraçáo ou aquelas relacionadas ao voluntariado. O lazer é composto pelas atividades não obrigatórias que realizamos nos momentos livres, ou seja, momentos em que náo realizamos nenhuma das atividades descritas anteriormente. A participação social é caracterizada pelo envolvimento do indivíduo em atividades na comunidade, na família e em seus ciclos de amizade/coleguismo (AMERICAN..., 2014).

A fim de promover o envelhecimento com qualidade de vida e prevenir as perdas funcionais, tão comuns a essa população, os profissionais da área da saúde devem dispor de tecnologias que permitam realizar diagnósticos corretos, contribuindo assim para planos de intervençóes mais seguros e coesos (FONSECA; RIZZOTTO, 2008).

As avaliaçôes funcionais costumam descrever de forma ordenada as atividades típicas do cotidiano de um indivíduo, que pressupóem uma variedade de habilidades incluídas no desempenho destas atividades e são consideradas como uma tentativa sistematizada de avaliar, de forma objetiva, os níveis de desempenho dos indivíduos nestas atividades (FONSECA; RIZZOTTO, 2008).

Essas avaliaçóes contribuem para o processo diagnóstico, tanto clínico como terapêutico ocupacional, no acompanhamento do desempenho ocupacional desses idosos, além de fornecer subsídios para as intervençôes da Terapia Ocupacional no atendimento ao idoso e nas orientaçóes aos cuidadores/familiares (CANON; NOVELLI, 2012).

No processo de avaliação de indivíduos com síndromes demências, propóe-se a aplicação de um instrumento de avaliaçáo funcional e um teste cognitivo, visto que essa combinação aumenta a sensibilidade e a especificidade para rastrear a doença (NITRINI et al., 2005).

Essa combinação aponta a importância de termos disponíveis instrumentos de avaliação funcional, confiáveis e válidos, que abarquem o maior número de Ocupaçóes e suas respectivas atividades, visto que o desempenho ocupacional é amplo e heterogêneo.

Atualmente não há disponíveis na literatura nacional instrumentos de avaliação funcional em demência que abordem todas as Ocupaçóes. Encontram-se instrumentos direcionados especificamente para a avaliação de Ocupações como ABVD e AIVD, e mesmo assim não contemplam todas as atividades que fazem parte destes grupos. Além disso, os instrumentos presentes, em sua maioria, não contemplam todas as análises psicométricas necessárias para assegurar a qualidade e a fidedignidade destes (CANON; NOVELLI, 2012).

Diante deste cenário, é de suma importância a elaboração e análise das propriedades psicométricas de instrumentos de avaliação funcional que possibilitem a compreensão do desempenho ocupacional de idosos com demência de forma ampla e baseada no cotidiano destes sujeitos, salientando-se que esse cotidiano náo se limita às ABVD e AIVD.

O objetivo deste estudo foi elaborar Versão Longa da Escala de Avaliação de Incapacidade na Demência (DADL-Br), que contemple todas as Ocupaçóes previstas pela AOTA, bem como atividades que as compóem e que possam estar inseridas no cotidiano de idosos com demência, além de avaliar a sua validade de conteúdo.

\section{Método}

Trata-se de estudo de desenvolvimento de um instrumento de avaliação funcional, aprovado pelo Comitê de Ética em Pesquisa da Universidade Federal de São Paulo (UNIFESP) (processo: 311.416) e financiado pela Fundaçáo de Amparo à Pesquisa do Estado de São Paulo (FAPESP - processo 2013/10943-0). Todos os participantes foram informados sobre os objetivos da pesquisa, concordaram em participar do estudo e assinaram o Termo de Consentimento Livre e Esclarecido.

\subsection{Instrumento}

A Escala de Avaliação de Incapacidade na Demência (DAD-Br), ou o Disability Assessment for Dementia (DAD) (GÉLINAS et al., 1999; BAHIA et al., 2010), avalia, através da percepção do cuidador/familiar 
do idoso com demência, 40 itens de desempenho ocupacional, sendo 17 relacionados com ABVD, 22 relacionados às AIVD e 1 relacionado ao Lazer.

Para cada item avalia-se a presença (SIM) ou ausência (NÂO) de capacidade de iniciativa, de planejamento e de realizaçáo efetiva da tarefa. Prevê-se o uso da alternativa "não se aplica/sem resposta (NA)" caso o item não faça parte da rotina do idoso, e nesse caso o item é subtraído da pontuação total, para que não haja uma subavaliação do desempenho ocupacional do idoso.

A pontuação total é calculada utilizando-se a seguinte fórmula: total de respostas "SIM" divididas por 40 (referente ao número total de itens), menos o número de respostas "NA", vezes 100 (respostas "sim"/40 - respostas "NA" x 100). A pontuação máxima é de $100 \%$, e quanto maior o escore, melhor o desempenho ocupacional do idoso.

O DAD-Br é a versão em português do DAD e possui a mesma estrutura da versão original quanto às atividades e etapas para sua realização. Na avaliação das suas propriedades psicométricas, obteve índices de confiabilidade elevados (Kappa $=0,72 ; p<0,001$ para interexaminadores e Kappa $=0,85 ; p<0,001$ para intraexaminador) e boa consistência interna $(\alpha=0,77)$ (CARTHERY-GOULART et al., 2007; BAHIA et al., 2010).

Apesar de ser considerado o mais completo, muitas Ocupaçôes e atividades que estâo presentes no cotidiano dos idosos náo são avaliadas no $\mathrm{DAD}-\mathrm{Br}$, podendo comprometer a compreensão global do desempenho ocupacional destes e, consequentemente, interferir no processo diagnóstico e plano de intervenção.

A elaboração da Versão Longa da Escala de Avaliação de Incapacidade na Demência (DADL-Br) foi autorizada pela autora principal da versáo original do DAD: Profa. Dra. Isabelle Gélinas - Terapeuta Ocupacional e Professora Associada à Universidade McGill em Quebec, Canadá.

Na proposição do DADL-Brforam incluídos itens previstos na classificação da AOTA, sendo estes referentes às Ocupaçóes, atividades e/ou tarefas que contemplam o cotidiano da população idosa, com base no contexto cultural brasileiro. Manteve-se a proposta de avaliação dos itens como na versão original e que consideram a capacidade de iniciativa, organização e planejamento e a realização efetiva de cada atividade, os critérios adotados para a sua aplicação, com relação ao desempenho do idoso nos últimos 15 dias e o cálculo para a pontuação final, em porcentagem.

\subsection{Processo de adaptação transcultural e avaliação das propriedades psicométricas}

A adaptação transcultural, a confiabilidade e a validade são atributos propostos pelo Scientific Advisory Committee of the Medical Outcomes Trust - SAC (SCIENTIFIC..., 2002) e fundamentais para a escolha de um instrumento de avaliaçáo. A ausência destes atributos pode refletir diretamente na informação advinda do instrumento, interferindo no diagnóstico, na definiçáo de condutas terapêuticas e na elaboração do plano de intervençáo, chegando a comprometer a eficácia e a eficiência dos tratamentos oferecidos (GIUSTI; BELFI-LOPES, 2008).

As adaptaçôes transculturais e de linguagem são aspectos a serem considerados para se revisar um instrumento. Este processo é composto pela tradução do instrumento, a retrotradução (tradução para a língua original), análise por um comitê de especialistas, que é responsável por avaliar as equivalências semânticas que representam a equivalência com relação ao vocabulário e à gramática; equivalência idiomática que se refere às expressóes idiomáticas e coloquiais, que devem estar de acordo com o contexto e a cultura para qual o instrumento está sendo traduzido; equivalência cultural que avalia se as situaçóes retratadas estão coerentes com o contexto cultural, e a equivalência conceitual, que se refere à coerência do item em avaliar o que está sendo proposto (GUILLEMIN; BOMBARDIER; BEATON, 1993; ALEXANDRE; COLUCI, 2011).

Após a análise do comitê de especialistas, o instrumento deve ser submetido a uma análise dos autores da versão original para que seja possível identificar alguma discrepância no processo de adaptação que altere os construtos e conceitos do instrumento (BEATON et al., 2000). A fase do pré-teste tem como o objetivo identificar possíveis falhas de compreensão e dificuldades encontradas em sua aplicação, por parte da população-alvo da avaliação e também por parte dos examinadores (GUILLEMIN; BOMBARDIER; BEATON, 1993; ALEXANDRE; COLUCI, 2011).

A finalização deste processo de adaptação transcultural confere a validade de conteúdo ao instrumento, verificando se seus itens se ajustam aos seus objetivos.

A validação do conteúdo é essencial no desenvolvimento de novas medidas, pois possibilita 
a associação de conceitos abstratos com indicadores possíveis de observar e mensurar. Uma das definiçôes mais abrangentes na literatura para validação do conteúdo aponta que esta é a capacidade de avaliar o grau com que cada elemento de um instrumento é relevante e representativo de determinado construto (ALEXANDRE; COLUCI, 2011).

A primeira etapa é caracterizada pela definição do construto de interesse e suas dimensôes através da pesquisa bibliográfica (ALEXANDRE; COLUCI, 2011).

Um estudo realizado por Canon e Novelli (2012) constatou que 15 instrumentos de avaliação funcional são comumente utilizados no Brasil para avaliar idosos com demência. Destes, quatro avaliam AIVD; três ABVD; quatro ABVD e AIVD; três ABVD, AIVD e Lazer e um ABVD e Lazer, evidenciando a falta de instrumentos que avaliem as demais Ocupaçóes propostas pelo documento da AOTA, por exemplo, Descanso e Sono, Trabalho, Educação e Participação Social, como também a falta de um instrumento único que contemple todas as Ocupaçóes.

Como resultado deste estudo, pôde-se identificar que 12 instrumentos foram adaptados transculturalmente, nove apresentam dados de confiabilidade e cinco dados de validade, sendo que um instrumento apresentou validade para a população com lesóes cerebrais e não para demência. Esses resultados apontam para a necessidade de estudos sobre a avaliação das propriedades psicométricas dos instrumentos utilizados, uma vez que 11 dos instrumentos selecionados não foram validados para o seu uso com idosos diagnosticados com demência, apesar de serem frequentemente utilizados em estudos com essa população (CANON; NOVELLI, 2012).

A partir da análise das propriedades psicométricas dos 15 instrumentos identificados, o DAD-Br foi considerado o mais completo e com uma metodologia de avaliação que nos permite identificar o impacto do funcionamento executivo sobre as atividades. Apesar de ser considerado o mais completo, muitas Ocupaçôes e atividades que estão presentes no cotidiano dos idosos náo são consideradas nessa versão, o que justifica a proposição de uma versão longa do DAD-Br com a inclusão dos domínios e itens que atualmente não compóem o instrumento.

\subsection{Procedimentos}

O processo de elaboração do DADL-Br utilizou como referencial de embasamento teórico a metodologia proposta por Beaton et al. (2000) para adaptaçóes transculturais. Por não se tratar de uma tradução e sim da criaçáo de novos itens, utilizaram-se algumas etapas desta metodologia, sendo estas: avaliação das equivalências cultural e conceitual dos itens gerados, uma vez que é o pré-teste que busca identificar a compreensão e entendimento dos novos itens.

Foram organizados dois Comitês para análise das equivalências dos itens elaborados para as Ocupaçóes previstas na AOTA: Comitê de Especialistas e Comitê Multiprofissional. O primeiro foi composto por cinco Terapeutas Ocupacionais com ampla experiência na área de Gerontologia (três Professoras Doutoras, uma Mestre e uma Especialista), o segundo, composto por quatro profissionais da área da saúde, sendo uma Geriatra, uma Enfermeira, uma Fonoaudióloga e uma Fisioterapeuta.

Para as avaliaçôes das Equivalências foram disponibilizados, para ambos os Comitês, o documento da AOTA (AMERICAN..., 2008) que fundamentou a elaboraçáo dos itens, a versão em português (DAD-Br), a Versão Longa (DADL-Br) e o questionário de avaliação das Equivalências correspondente a cada comitê. O Comitê de Especialistas avaliou as Equivalências Conceitual e Cultural, e o Comitê Multidisciplinar apenas a Equivalência Cultural. Essa divisão foi estabelecida a partir do raciocínio de que o documento utilizado para a geraçáo dos itens é um documento próprio da área de Terapia Ocupacional, sendo que o Comitê de Especialistas seria o mais indicado para a avaliação da equivalência conceitual dos itens gerados.

Nos questionários de avaliação das equivalências, os juízes opinaram sobre cada um dos novos itens, orientados pelas seguintes alternativas e respectivas pontuaçôes: -1: não há equivalência; 0 : indeciso e +1 : o item é equivalente. Para os itens pontuados com 0 ou -1 , foi solicitado aos juízes que sugerissem as alteraçôes que julgassem necessárias para o melhor entendimento do item.

O prazo estabelecido ao Comitê de Especialistas para o envio de cada avaliação foi de 30 dias e para o Comitê Multiprofissional, 60 dias.

Os itens foram considerados equivalentes ao obter no mínimo $80 \%$ de concordância entre os juízes do Comitê de Especialistas e 75\% entre os juízes do Comitê Multiprofissional. A porcentagem de concordância foi menor para o Comitê Multiprofissional, uma vez que este foi composto por um número menor de juízes.

O valor da concordância é denominado Índice de Validade de Conteúdo (IVC). Os itens com um IVC abaixo do mínimo estabelecido foram modificados/ adaptados de acordo com as sugestóes propostas pelos juízes (RUBIO; BERG-WEGER; LEE, 2003). 
Cabe ressaltar que a autora principal da versão original do instrumento DAD participou da elaboração da Primeira Versão do DADL-Br, assim como analisou o instrumento novamente após as avaliaçóes realizadas por ambos os Comitês.

Após a avaliação dos especialistas, seguiu-se para a fase do pré-teste. O percentual de compreensão para os itens nos pré-testes foi estabelecido em $90 \%$, e foram realizados três pré-testes (BEATON et al., 2000).

O processo de análise das equivalências, pré-testes e análise da autora principal teve duração de aproximadamente um ano.

\section{Resultados}

A seguir serão apresentados resultados das distintas etapas do estudo. $\mathrm{O}$ processo de elaboração do DADL-Br teve início com a elaboração de novos itens com base na classificação da AOTA para as Ocupaçōes. A Tabela 1 apresenta as Ocupações e suas respectivas atividades, conforme descrito nessa classificação (AMERICAN..., 2014).

A Primeira Versáo elaborada pelas pesquisadoras contemplava 10 novos domínios e 64 novos itens, que foram divididos entre os novos domínios e os já existentes.

Tabela 1. Ocupações e suas respectivas atividades, segundo a classificação da American Occupational Therapy Association.

\begin{tabular}{|c|c|}
\hline Ocupações & Atividades \\
\hline Atividades Básicas da Vida Diária (ABVD) & $\begin{array}{l}\text { Banho; } \\
\text { Controle de Esfincteres; } \\
\text { Vestir-se; } \\
\text { Comer; } \\
\text { Alimentação; } \\
\text { Mobilidade Funcional; } \\
\text { Cuidado com Equipamentos Pessoais; } \\
\text { Higiene Pessoal e Autocuidado; } \\
\text { Atividade Sexual; } \\
\text { Uso do Vaso Sanitário. }\end{array}$ \\
\hline $\begin{array}{l}\text { Atividades Instrumentais da Vida Diária } \\
\text { (AIVD) }\end{array}$ & $\begin{array}{l}\text { Cuidado com outros; } \\
\text { Cuidado com animais; } \\
\text { Educar criança; } \\
\text { Gerenciamento de comunicação; } \\
\text { Mobilidade na comunidade; } \\
\text { Gerenciamento financeiro; } \\
\text { Gerenciamento e manutenção da saúde; } \\
\text { Estabelecimento e gerenciamento do lar; } \\
\text { Preparo da refeição e limpeza; } \\
\text { Costumes religiosos; } \\
\text { Manutenção da segurança e emergência; } \\
\text { Fazer compras. }\end{array}$ \\
\hline Descanso e Sono & $\begin{array}{l}\text { Preparação para dormir/descansar; } \\
\text { Participação no dormir/descansar. }\end{array}$ \\
\hline Educação & $\begin{array}{l}\text { Participação na educação formal; } \\
\text { Exploração das necessidades e/ou interesses educacionais } \\
\text { pessoais informais (além da educação formal); } \\
\text { Participação pessoal informal na educação. }\end{array}$ \\
\hline Trabalho & $\begin{array}{l}\text { Interesse e busca por emprego; } \\
\text { Procura e aquisição de emprego; } \\
\text { Desempenho no papel; } \\
\text { Preparação e adequação para a aposentadoria; } \\
\text { Interesse por voluntariado; } \\
\text { Participação em voluntariado. }\end{array}$ \\
\hline Lazer & $\begin{array}{l}\text { Exploração para o lazer; } \\
\text { Participação no lazer. }\end{array}$ \\
\hline Participação Social & $\begin{array}{l}\text { Comunidade; } \\
\text { Família; } \\
\text { Coleguismo/amizade. }\end{array}$ \\
\hline
\end{tabular}


Destes itens, cinco foram considerados de observação, nos quais são mapeadas informaçôes relevantes para um plano de intervenção adequado ao repertório ocupacional do sujeito. Esses correspondem aos equipamentos pessoais utilizados, hábitos de vida saudáveis, atividades religiosas realizadas, cursos de interesse, tipo e local de trabalho.

Além disso, o domínio Medicaçóes passou a ser classificado como Manutenção da Saúde, assim como descrito no documento da AOTA, uma vez que outras atividades e tarefas náo relacionadas à medicação foram incluídas neste domínio.

A Tabela 2 apresenta os domínios existentes no $\mathrm{DAD}-\mathrm{Br}$, atividades e/ou tarefas incluídas nesses domínios e novos domínios incluídos na Primeira Versão do DADL-Br.

A Primeira Versão do DADL-Br foi encaminhada ao Comitê de Especialistas. Com relação à primeira avaliaçáo de Equivalência Cultural, oito itens apresentaram IVC abaixo de $80 \%$, e com relação à Equivalência Conceitual, 10 itens, sendo que sete itens apresentaram IVC abaixo de $80 \%$ em ambas as Equivalências.

A média da concordância dos itens com relação à Equivalência Cultural foi de 89,4\% e da Equivalência Conceitual foi de $85 \%$.

Na segunda avaliaçáo das Equivalências, dos 18 itens avaliados, quatro apresentaram IVC abaixo de $80 \%$, sendo dois para Equivalência Cultural e dois para Equivalência Conceitual.

Nessa fase, os juízes opinaram sobre a exclusão do item "organização e planejamento das transferências posturais durante o uso do vaso sanitário", com base em comentários e sugestôes da primeira avaliação.

A média da concordância dos itens na segunda avaliação, com relaçáo à Equivalência Cultural, foi de $90 \%$ e da Equivalência Conceitual foi de 85\%.
Para a terceira avaliaçáo foram encaminhados quatro itens. O item "planejamento e organização para a realização da atividade sexual" foi avaliado quanto a sua exclusão, uma vez que os juízes opinaram sobre ela na segunda avaliação.

Apenas o item "planejamento para o uso dos equipamentos pessoais" apresentou IVC abaixo de $80 \%$ para Equivalência Conceitual, foi modificado conforme as sugestôes dos especialistas, que neste caso foram semelhantes, assim não houve necessidade de nova avaliação para este item. A média da concordância dos itens com relação à Equivalência Cultural foi de $100 \%$ e da Equivalência Conceitual foi de $85 \%$.

Com base nas três avaliaçóes realizadas, a Segunda Versão do DADL-Br foi elaborada. Em síntese, nessa versão mantiveram-se 10 novos domínios e 66 itens (dos 64 itens propostos pelos pesquisadores, dois itens foram excluídos e quatro acrescentados). Esta versão foi então encaminhada ao Comitê Multiprofissional, que avaliou a Equivalência Cultural dos itens.

Nesta avaliação, apenas três itens receberam IVC abaixo de $75 \%$. Quanto ao item "planejamento e organização para mobilidade funcional", as pesquisadoras optaram por excluí-lo, caso o pré-teste confirmasse a dificuldade na compreensão dele, e os outros dois, "iniciativa para uso e limpeza dos equipamentos pessoais”, foram modificados.

Um juiz recomendou a inclusão de itens para avaliar a marcação de consultas e/ou atendimentos com profissionais da saúde, atividade muito presente no cotidiano dos idosos. As pesquisadoras julgaram a sugestão de extrema relevância e elaboraram uma nova avaliação das Equivalências Cultural e Conceitual a ser respondida pelo Comitê de Especialistas. A média da concordância dos itens com relação à Equivalência Cultural foi de 93\%.

Tabela 2. Domínios que compõem o DAD-Br, atividades e/ou tarefas incluídas nesses domínios e novos domínios incluídos no DADL-Br.

\begin{tabular}{|c|c|c|}
\hline Domínios Presentes no DAD-Br & $\begin{array}{c}\text { Domínios Incluídos } \\
\text { no DADL-Br }\end{array}$ & $\begin{array}{l}\text { Domínios Existentes, nos quais } \\
\text { foram incluídas atividades e/ou } \\
\text { tarefas }\end{array}$ \\
\hline $\begin{array}{l}\text { - Higiene; } \\
\text { - Vestir-se; } \\
\text { - Continência; } \\
\text { - Alimentar-se; } \\
\text { - Preparação da Refeição; } \\
\text { - Uso do telefone; } \\
\text { - Atividade Fora de Casa; } \\
\text { - Finanças e Correspondências; } \\
\text { - Medicações; } \\
\text { - Lazer e Tarefas de Casa. }\end{array}$ & $\begin{array}{l}\text { - Mobilidade Funcional; } \\
\text { - Cuidados com Equipamentos } \\
\text { Pessoais; } \\
\text { - Atividade Sexual; } \\
\text { - Sono e Descanso; } \\
\text { - Cuidar de Outros; } \\
\text { - Cuidar de Animais; } \\
\text { - Atividades Religiosas; } \\
\text { - Educação; } \\
\text { - Trabalho; } \\
\text { - Participação Social. }\end{array}$ & $\begin{array}{l}\text { - Higiene; } \\
\text { - Continência; } \\
\text { - Preparação da Refeição; } \\
\text { - Medicações (passou a ser } \\
\text { classificado como Manutenção da } \\
\text { Saúde); } \\
\text { - Lazer e Tarefas de Casa. }\end{array}$ \\
\hline
\end{tabular}


Para a quarta avaliação foram encaminhados ao Comitê de Especialistas três novos itens referentes a iniciativa, planejamento e efetiva realização para o item de marcação de consultas ou atendimentos com profissionais da saúde. A média da concordância dos itens com relação à Equivalência Cultural foi de $87 \%$ e da Equivalência Conceitual foi de $60 \%$.

Os três itens obtiveram baixa concordância para a Equivalência Conceitual e foram modificados com base nas sugestóes dos juízes, que foram semelhantes, por isso as pesquisadoras concluíram não haver a necessidade de nova avaliação.

Após a análise das avaliações realizadas pelos Comitês, a Terceira Versão do DADL-Br foi elaborada. Os 10 novos domínios mantiveram-se e os 66 novos itens resultaram em 68 (um item foi excluído e três acrescentados).

Com esta nova versão, foi realizado o primeiro pré-teste com sete cuidadores de idosos com demência. O percentual médio de compreensão dos itens foi de $97,1 \%$, apenas um item apresentou percentual abaixo de $90 \%$, justamente o referente ao planejamento da mobilidade funcional, e como sugerido pelo Comitê Multiprofissional, o item foi excluído.

Outros quatro itens foram excluídos devido à reorganização de seus conteúdos. Sendo assim agruparam-se itens referentes aos domínios planejamento e organização de tarefas de Higiene, Descanso e Sono e, Educaçáo, pois o planejamento e organização para separação de itens de higiene, assim como referentes ao descanso, ao dormir e os utilizados em cursos, săo semelhantes.

Após o primeiro pré-teste, a Quarta Versão do DADL-Br foi elaborada. Os 10 novos domínios mantiveram-se e o número de itens foi reduzido para 64 (quatro itens foram excluídos).

A Quarta Versão foi aplicada por meio de um segundo pré-teste em cinco novos cuidadores de idosos com demência e obteve-se um percentual de $100 \%$ de entendimento dos itens.

Após o segundo pré-teste, a Quarta Versão do instrumento foi traduzida para o inglês e encaminhada à autora principal da versão original, que sugeriu a inclusão de dois itens: o uso da internet e dos caixas eletrônicos para serviços bancários no domínio Finanças e Correspondências já existente no DAD-Br.

As pesquisadoras aceitaram a sugestão e incorporaram ao instrumento o uso do computador e equipamentos similares (como o tablet) no domínio Uso do Telefone, que passou a ser classificado como Equipamentos Eletrônicos.

Com isso, cinco novos itens foram criados e encaminhados ao Comitê de Especialistas para análise das Equivalências Cultural e Conceitual.
Assim, para a quinta avaliação das Equivalências foram encaminhados três novos itens referentes a iniciativa, planejamento e efetiva realização no uso de computadores e equipamentos similares, e dois itens incluídos no domínio Finanças e Correspondências para avaliar o uso da internet banking e caixa eletrônico para serviços bancários.

Foi proposta também a mudança da nomenclatura do domínio Uso do Telefone para Equipamentos Eletrônicos, porém um dos juízes destacou que essa terminologia é muito ampla, envolvendo o uso de diversos equipamentos.

Os três itens propostos neste domínio (Uso do Telefone/Equipamentos Eletrônicos) apresentaram IVC abaixo de $80 \%$ para ambas Equivalências. A média da concordância dos itens em relação à Equivalência Cultural e Conceitual foi de 72\%.

Para a sexta avaliaçáo, foram encaminhados os três novos itens reestruturados do domínio Uso do Telefone/Equipamentos Eletrônicos. Nesta avaliação, foi sugerida e aceita a mudança de sua nomenclatura para Gerenciamento de Comunicação, conforme terminologia adotada pela AOTA. A média da concordância dos itens com relação à Equivalência Cultural foi de 93,3\% e da Equivalência Conceitual foi de $100 \%$.

A partir desta avaliação, foi elaborada a Quinta Versão do DADL-Br, contemplando 20 domínios, sendo destes 10 novos e 109 itens, sendo destes 69 novos. Essa versão foi aplicada em um terceiro pré-teste a cinco novos cuidadores/familiares de idosos com demência e obteve um percentual de $100 \%$ de entendimento dos itens, concluindo assim o processo de Validação de Conteúdo do DADL-Br e resultando na versão final do instrumento.

O organograma a seguir apresenta o resumo dos processos realizados na primeira etapa do estudo (Figura 1).

A Tabela 3 apresenta os domínios existentes no $\mathrm{DAD}-\mathrm{Br}$, os novos domínios, que em conjunto com os anteriores compóem a Versão Final DADL-Br, e aqueles nos quais foram incluídas novas atividades e/ou tarefas.

\section{Discussão}

A tradução de instrumentos em outras línguas vem substituindo a criação de novos. Atualmente, um dos aspectos considerados pelos editores na criação de um novo teste tem sido a possibilidade da tradução deste para outros idiomas (GIUSTI; BELFI-LOPES, 2008). Por isso, na literatura atual há poucos estudos que abordam a criação 


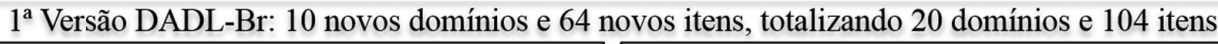
$\sqrt{2}$

Primeira Avaliação das Equivalências Cultural e Conceitual - COMITE DE ESPECIALISTAS: reformulação de 11 itens com IVC abaixo de $80 \%$ e inclusão de 4 itens

$$
5
$$

Segunda Avaliação das Equivalências Cultural e Conceitual - COMITÊ DE ESPECIALISTAS: reformulação de 4 itens com IVC abaixo de $80 \%$ e exclusão de 1 item

5

Terceira Avaliação das Equivalências Cultural e Conceitual - COMITÊ DE ESPECIALISTAS: reformulação de 1 item com IVC abaixo de $80 \%$ e exclusão de 1 item

$2^{\text {a }}$ Versão DADL-Br: 10 novos domínios e 66 novos itens ( 2 itens excluídos e 4 itens acrescentados), totalizando 20 domínios e 106 itens

Avaliação da Equivalência Cultural - COMITE MULTIPROFISSIONAL: reformulação de 2 itens com IVC abaixo de $75 \%$, exclusão de 1 item e inclusão de 3

Quarta Avaliação das Equivalências Cultural e Conceitual - COMITÊ DE ESPECIALISTAS: reformulação dos 3 itens propostos, que obtiveram IVC abaixo de $80 \%$

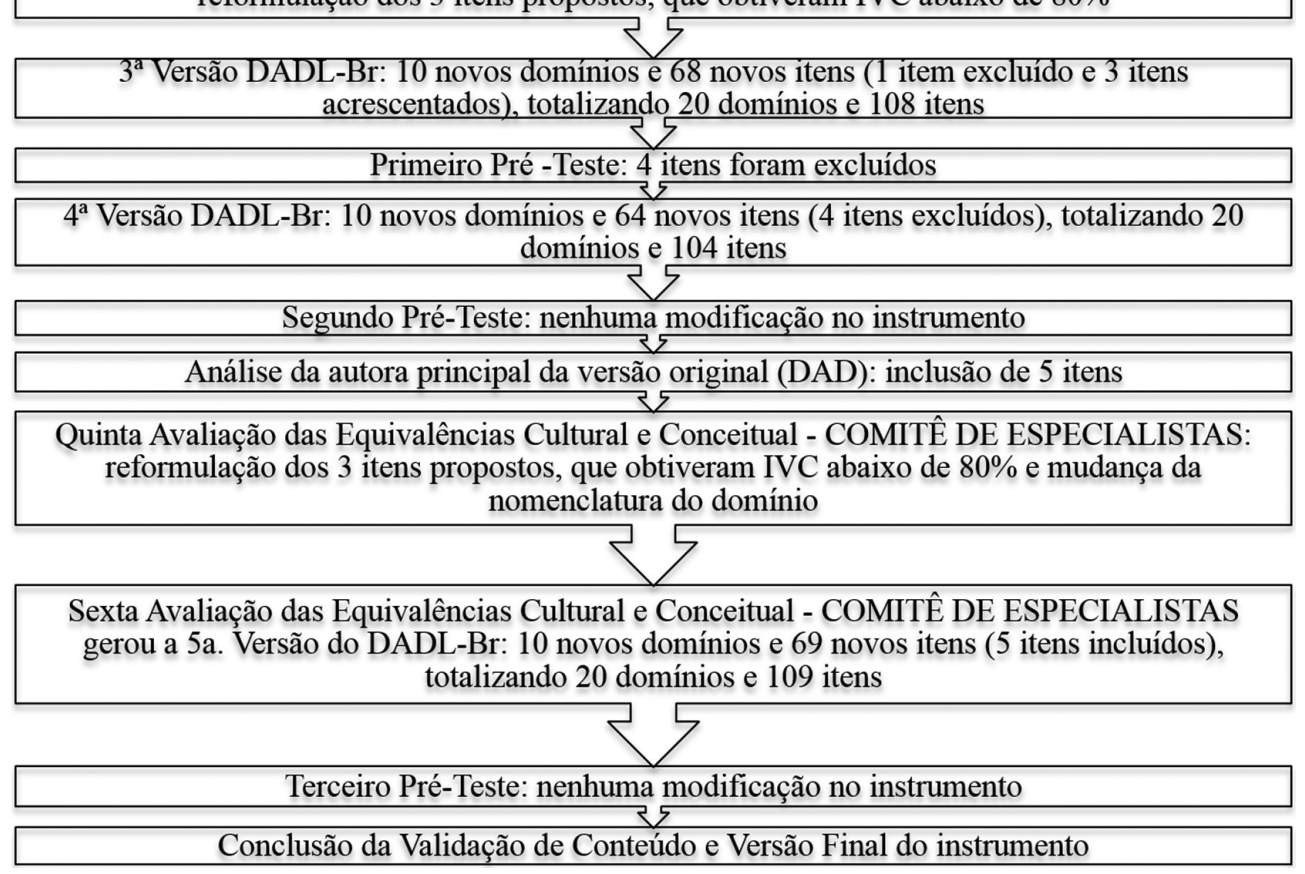

Figura 1. Organograma dos processos e resultados da primeira etapa do estudo.

Tabela 3. Domínios que compõem o DAD-Br, os novos itens incluídos e aqueles nos quais foram acrescentas outras tarefas (Quinta Versão DADL-Br).
10 Domínios Presentes no
DAD-Br
10 Domínios Incluídos no
DADL-Br

- Higiene;

- Vestir-se;

- Continência;

- Alimentar-se;

- Preparação da Refeição;

- Uso do telefone;

- Atividade Fora de Casa;

- Finanças e Correspondências;

- Medicações;

- Lazer e Tarefas de Casa.

Total de Itens: 40
- Mobilidade Funcional;
- Cuidados com Equipamentos
Pessoais;
- Atividade Sexual;
- Sono e Descanso;
- Cuidar de Outros;
- Cuidar de Animais;
- Atividades Religiosas;
- Educação;
- Trabalho;
- Participação Social.
Total de Itens: 46

Domínios Existentes, nos quais foram incluídas atividades e/ou tarefas

- Higiene;

- Continência;

- Preparação da Refeição;

- Medicações (passou a ser classificado como Manutenção da Saúde);

- Uso do Telefone (passou a ser classificado como Gerenciamento de Comunicação);

- Finanças e Correspondências;

- Lazer e Tarefas de Casa.

Total de Itens: $\mathbf{2 3}$ 
de instrumentos, a maioria dos estudos se propóe a realizar adaptaçóes transculturais e análise das propriedades psicométricas das versóes adaptadas.

Com base na revisão bibliográfica, na classificaçáo proposta pela AOTA e em métodos padronizados para criação de medidas cognitivas, descritos pela literatura (ALEXANDRE; COLUCI, 2011), foi possível identificar os domínios que faltavam ser avaliados na versáo original adaptada para uso no Brasil (DAD-Br), formular e organizar novos itens e construir assim uma proposta de Versão Longa (DADL-Br).

Após a criação dos itens, seguiram-se as avaliações das Equivalências do DADL-Br por um Comitê de Especialistas, que promoveu um feedback construtivo sobre a qualidade desses novos itens, além de proporcionar sugestôes para a melhoria do instrumento. Algumas limitaçôes com relação a esse comitê são apontadas, como o fato de o feedback ser subjetivo; como cada especialista tem uma opiniáo, com isso alguns vieses podem ser encontrados entre eles (RUBIO; BERG-WEGER; LEE, 2003).

Os especialistas são selecionados com base em seus trabalhos e publicações na área do instrumento a ser desenvolvido, por isso o rigor em convidar profissionais com ampla experiência na área, o que resultou em três Professoras Doutoras, uma Mestre e uma Especialista. Com relação ao número de profissionais que devem compor o comitê, há divergências na literatura, apresentando uma variação de três a vinte especialistas, sendo que alguns autores sugerem o número mínimo de cinco (RUBIO; BERG-WEGER; LEE, 2003; ALEXANDRE; COLUCI, 2011), o que foi considerado por esse estudo na organização dos comitês.

Nos processos de adaptação transcultural, recomenda-se que o comitê seja multiprofissional. Apesar de não se tratar de uma adaptação e sim da criação de uma versão longa do instrumento, as pesquisadoras consideraram de extrema relevância a participação de outros profissionais, além dos Terapeutas Ocupacionais, nos processos de avaliação (GUILLEMIN; BOMBARDIER; BEATON, 1993).

As avaliaçóes pelos comitês envolvem procedimentos quantitativos e qualitativos, e os juízes os que compóem devem estar cientes das regras para a avaliação dos itens. Espera-se que eles sejam capazes de verificar se o conjunto de itens está avaliando adequadamente cada domínio, se cada item individualmente está claro e pertinente, se são relevantes e adequados para se alcançar os objetivos propostos. Sugere-se também que se ofereça um espaço para que os juízes coloquem suas sugestóes e comentários (RUBIO; BERG-WEGER; LEE, 2003; ALEXANDRE; COLUCI, 2011).
Os itens foram avaliados em relação às Equivalências Conceituais e Culturais, e os juízes teceram também consideraçóes sobre a semântica (relativa ao significado das palavras, vocabulário e gramática) do instrumento (ALEXANDRE; COLUCI, 2011).

Nesta fase é esperado que ocorram modificações no instrumento, eliminando-se alguns itens e acrescentando ou se modificando outros (RUBIO; BERG-WEGER; LEE, 2003; ALEXANDRE; COLUCI, 2011). Tais modificaçôes ocorreram ao longo de sete avaliaçóes realizadas pelos Comitês, resultando em um acréscimo de doze itens e na exclusão de sete, evidenciando a complexidade e o rigor para se criar itens que estejam adequados não apenas aos objetivos propostos pelo instrumento como também ao contexto cultural no qual o mesmo está inserido.

Dentre as metodologias utilizadas para quantificar o grau de concordância entre os especialistas, destaca-se a porcentagem de concordância por ser a mais utilizada (ALEXANDRE; COLUCI, 2011).

Com relação à taxa aceitável de concordância, alguns autores sugerem 90\% (ALEXANDRE; COLUCI, 2011), outros 80\% (PAULA et al., 2013), porém, no caso deste estudo, utilizar uma taxa de $90 \%$ seria obter a concordância entre todos os juízes, por isso, optou-se por utilizar a taxa de $80 \%$ para o Comitê de Especialistas e $75 \%$ para o Comitê Multiprofissional, que contou com um profissional a menos.

Destaca-se que as médias de concordância de ambos os Comitês apresentaram valores elevados; apenas em duas das avaliaçóes do Comitê de Especialistas a média foi abaixo de $80 \%$.

Ressalta-se que as principais sugestôes de adaptação e modificaçóes dos itens em ambos os Comitês referiram-se à simplificação do conteúdo; substituição de palavras; detalhamento do planejamento; exclusão e inclusão de itens; separação de domínios; exemplificaçáo de termos.

A versão final do DADL-Br contempla todas as Ocupaçóes descritas pela AOTA, como ABVD, AIVD, Descanso e Sono, Lazer, Educação, Trabalho e Participação Social que estáo organizadas em 20 domínios e 109 itens, sendo seis itens de observação, propondo-se desse modo ser o mais fiel possível ao cotidiano dos idosos. Considerando que o universo ocupacional, mesmo de idosos com demência, não se limita ao desempenho de ABVD e AIVD, o instrumento inclui as diversas atividades que estes podem realizar e possibilita mapear o perfil de desempenho ocupacional desses idosos, ao avaliar as atividades que compóem as Ocupações e o impacto do funcionamento executivo sobre esse desempenho 
ao avaliar as capacidades de iniciativa, organização e planejamento e realização efetiva dessas atividades.

As ABVD abrangem sete domínios e 34 itens; Sono e Descanso, um domínio e cinco itens; AIVD, oito domínios e 49 itens; Lazer, um domínio com quatro itens; Educação, um domínio e seis itens; Trabalho, um domínio e quatro itens, e Participação Social, com um domínio e sete itens.

A pontuação é avaliada através de porcentagem, sendo que as pontuaçóes mais altas predizem um melhor desempenho ocupacional.

Por ser um instrumento de avaliação amplo, o profissional tem a opção de selecionar os domínios que deseja avaliar e que compóem o cotidiano dos idosos em processo de avaliação, gerando uma pontuação para o(s) mesmo(s), utilizando o mesmo raciocínio que orienta o cálculo da pontuação total. Além disso, é possível ter pontuaçôes separadas por domínios, o que facilita o raciocínio clínico do Terapeuta Ocupacional no planejamento da intervenção.

O DADL-Br evidencia a importância de avaliar de forma ampla o desempenho ocupacional dos idosos com demência, pois este é influenciado por diversos aspectos que muitas vezes náo são considerados pela maioria dos instrumentos de avaliação funcional, e que são fundamentais para acompanhar e compreender a progressão da doença e o consequente declínio no desempenho.

Destaca-se que este instrumento (DADL-Br), assim como a versão original (DAD) e a adaptada para o português para o uso no Brasil (DAD-Br), são instrumentos que avaliam o desempenho ocupacional e que não consideram apenas a capacidade ou não do sujeito para realizar determinada atividade, mas também a influência de aspectos cognitivos tão relevantes, como as funçôes executivas, no desempenho dessas atividades.

Muitas atividades e/ou Ocupaçóes podem ser adaptadas ou graduadas de acordo com o declínio funcional e cognitivo para postergar a dependência e/ou exclusão destas do cotidiano dos sujeitos, promovendo e maximizando a independência, a autonomia e o senso de utilidade destes idosos.

Para que isso ocorra, devemos destacar a importância náo apenas de instrumentos completos e amplos, mas também de reavaliaçóes periódicas que permitam esse acompanhamento detalhado.

Ressalta-se que o número de juízes de ambos os Comitês, que avaliaram as Equivalências, poderia ser maior, e isso pode ser considerado como uma limitação do estudo, porém a escassez de profissionais qualificados e que estivessem disponíveis para participar das avaliaçóes de Equivalência dificultou a ampliação do número de juízes.

\section{Conclusão}

Considera-se que o processo de elaboração e avaliação do DADL-Br, por ter seguido as etapas requeridas pela literatura, tenha conferido Validade de Conteúdo ao instrumento e que este possa vir a constituir-se em uma ferramenta útil para acompanhar e avaliar o desempenho ocupacional de idosos com demência, uma vez que contempla todas as Ocupaçóes propostas pela AOTA, assim como uma ampla variedade de atividades presentes no cotidiano de idosos brasileiros com demência.

O DADL-Br é um instrumento novo, e estudos relacionados a sua aplicabilidade e análises psicométricas devem ser conduzidos. Deste modo, novas pesquisas estão sendo realizadas para ampliar as análises das propriedades psicométricas, com relação à confiabilidade (inter e intraexaminador) e validade de construto.

\section{Referências}

ALEXANDRE, N. M. C.; COLUCI, M. Z. O. Validade de conteúdo nos processos de construção e adaptação de instrumentos de medidas. Ciência e Saúde Coletiva, Rio de Janeiro, v. 16, n. 7, p. 3061-3068, 2011. Disponível em: <http://www.scielo.br/scielo.php?script=sci_ arttext\&pid=S1413-81232011000800006\&lng=en > . Acesso em: 29 set. 2014.

AMERICAN OCCUPATIONAL THERAPY ASSOCIATION - AOTA. Occupational therapy practice framework: domain and process 2 nd ed. American Journal of Occupational Therapy, Bethesda, v. 62, n. 1, p. 625683, 2008.

AMERICAN OCCUPATIONAL THERAPY ASSOCIATION - AOTA. Occupational therapy practice framework: domain and process. American Journal of $O c$ cupational Therapy, Bethesda, v. 68, n. 1, p. 1-48, 2014.

ARAÚJO, A. C.; LOTUFO NETO, F. A nova classificação americana para os Transtornos Mentais - o DSM5. Revista Brasileira de Terapia Comportamental e Cognitiva, São Paulo, v. 16, n. 1, p. 67-82, 2014. Disponível em: <http://www.usp.br/rbtcc/index.php/RBTCC/article/viewFile/659/406>. Acesso em: 29 set. 2014.

BAHIA, V. S. et al. Functional disability in Alzheimer disease a validation study of the Brazilian version of the Disability Assessment for Dementia (DAD-Br). Alzheimer Disease and Associated Disorders, Lawrence, v. 24 n. 3, p. 291-295, 2010. Disponível em: <http://journals. lww.com/alzheimerjournal/pages/articleviewer.aspx?yea $\mathrm{r}=2010$ \&issue $=07000$ \&article $=00012$ \& type $=$ abstract $>$. Acesso em: 06 out. 2014.

BEATON, D. E. et al. Guidelines for the process of cross-cultural adaptation of self-report measures. SPINE, Hangerstow, v. 25, n. 24, p. 3186-3191, 2000. Disponível em: <http://www.emgo.nl/kc/preparation/ 
research\%20design/vragenlijsten/Beaton.pdf>. Acesso em: 6 out. 2014.

BURLÁ, C. et al. Panorama prospectivo das demências no Brasil: um enfoque demográfico. Ciência e Saúde Coletiva, Rio de Janeiro, v. 18, n. 10, p. 2949-2956, 2013. Disponível em: <http://www.scielosp.org/scielo.php?script=sci_arttext \&pid=S1413-81232013001800019\&lng=en\&nrm=iso $>$. Acesso em: 01 out. 2014.

CANON, M. B. F; NOVELli, M. M. P. C. Estudo dos instrumentos de avaliação funcional em demência comumente utilizados no Brasil. Revista de Terapia Ocupacional da Universidade de São Paulo, São Paulo, v. 23, n. 3, p. 253-262, 2012. Disponível em: <http://www. revistas.usp.br/rto/article/download/55640/59100>. Acesso em: 01 out. 2014.

CARTHERY-GOULART, M. T. et al. Adaptação transcultural da escala de avaliação de incapacidade em demência (Disability Assessment For Dementia - DAD). Arquivos de Neuro-Psiquiatria, São Paulo, v. 65, n. 3b, p. 916-919, 2007. Disponível em: <http://www.scielo.br/ scielo.php?script=sci_arttext $\&$ pid $=$ S0004-282X200700 0500038\&lng=en\&nrm=iso >. Acesso em: 06 out. 2014.

CIETO, B. B. et al. Dementia care in public health in Brazil and the world: a systematic review. Dementia \& Neuropsychologia, São Paulo, v. 8, n. 1, p. 4046, 2014. Disponível em: <http://www.redalyc.org/ pdf/3395/339531529007.pdf>. Acesso em: 03 out. 2014.

FONSECA, F. B.; RIZZOTTO, M. L. F. Construção de instrumento para avaliação sócio-funcional em idosos. Texto e Contexto - Enfermagem, Florianópolis, v. 17, n. 2, p. 365-373, 2008. Disponível em: <http://www. scielo.br/scielo.php?script=sci_arttext\&pid=S0104-07072008000200020\&lng=en>. Acesso em: 06 out. 2014 .

GÉLINAS, I. et al. Development of a functional measure for persons with Alzheimer's disease: the disability assessment for dementia. American Journal of Occupational Therapy, Bethesda, v. 53, n. 5, p. 471-481, 1999. Disponível em: <http://ajot.aota.org/article. aspx?articleid=1873462>. Acesso em: 06 out. 2014.

GIUSTI, E.; BELFI-LOPES, D. M. Tradução e adaptação transcultural de instrumentos estrangeiros para o Português Brasileiro (PB). Pró-Fono Revista de Atualização Cientifica, Barueri, v. 20, n. 3, p. 207-210, 2008. Disponível em: <http://www.scielo.br/pdf/pfono/ v20n3/en_12.pdf $>$. Acesso em: 07 out. 2014.
GUILLEMIN, F.; BOMBARDIER, C.; BEATON, D. Cross-cultural adaptation of health-related quality of life measures: literature review and proposed guidelines. Journal of Clinical Epidemiology, Oxford, v. 46, n. 12, p. 1417-1432, 1993. Disponível em: <https://www. printo.it/AA_Working\%20models/1_1993_JCE_Guillemin\%20translation\%20guidelines.PDF>. Acesso em: 07 out. 2014

NITRINI, R. et al. Diagnóstico de doença de Alzheimer no Brasil: avaliação cognitiva e funcional. Recomendaçóes do Departamento Científico de Neurologia Cognitiva e do Envelhecimento da Academia Brasileira de Neurologia. Arquivo de Neuro-Psiquiatria, São Paulo, v. 63, n. 3a, p. 720-727, 2005. Disponível em: <http://www. scielo.br/scielo.php?script $=$ sci_arttext $\&$ pid $=$ S0004 $-282 X 2005000400034 \& \operatorname{lng}=\mathrm{en}>$. Acesso em: 02 out. 2014.

ORGANIZAÇÃO DAS NAÇÓES UNIDAS - ONU. Department of Economic and Social Affairs, Population Division. World population ageing. New York: United Nations, 2013. Disponível em: <http://www.un.org/en/ development/desa/population/publications/pdf/ageing/ WorldPopulationAgeing2013.pdf>. Acesso em: 16 set. 2014.

ORGANIZAÇÃO MUNDIAL DA SAÚDE - OMS. Guia para o Dia Mundial da Saúde. Geneva: WHO, 2012. Disponível em: <http://www.afro.who.int/pt/ angola/press-materials/item/4452-guia-para-o-dia-mundial-da-saúde-7-de-abril-de-2012.html>. Acesso em: 16 set. 2014 .

PAULA, A. F. M. et al. Avaliação da capacidade funcional, cogniçáo e sintomatologia depressiva em idosos atendidos em ambulatório de Geriatria. Revista Brasileira de Clínica Médica, São Paulo, v. 11, n. 3, p. 212-218, 2013. Disponível em: <http://files.bvs.br/ upload/S/1679-1010/2013/v11n3/a3767.pdf>. Acesso em: 07 out. 2014 .

RUBIO, D. M.; BERG-WEGER, M.; LEE, E. S. Objectifying content validity: Conducting a content validity study in social work research. Social Work Research, Oxford, v. 27, n. 2, p. 94-104, 2003. Disponível em: <http://swr.oxfordjournals.org/content/27/2/94.short DOI: 10.1093/swr/27.2.94>. Acesso em: 08 out. 2014.

SCIENTIFIC ADVISORY COMMITTEE OF THE MEDICAL OUTCOMES TRUST - SAC. Assessing health status and quality-of-life instruments: attributes and review criteria. Quality of Life Research, New York, v. 11, n. 3, p. 193-205, 2002. Disponível em: <http://link.springer.com/article/10.1023\%2FA\% 3A1015291021312>. Acesso em: 06 out. 2014.

\section{Contribuição dos Autores}

Mariana Canon e Marcia Novelli são responsáveis pela concepção, execução e revisão do estudo. Maria Helena Morgani participou da revisão do texto. Todos os autores aprovaram a versão final do texto.

\section{Fonte de Financiamento}

Fundação de Amparo à Pesquisa do Estado de Sáo Paulo (FAPESP - processo no 2013/10943-0). 